\title{
MATCHING UP THE DATA ON EDUCATION WITH ECONOMIC GROWTH MODELS*
}

\section{Chris Papageorgiou and Fidel Pérez-Sebastián**}

WP-AD 2002-23

Correspondence: F. Pérez-Sebastián. Universidad de Alicante. Dpto. Fundamentos del Análisis Económico. Campus San Vicente del Raspeig. 03080 Alicante, Spain. E-mail: fidel@merlin.fae.ua.es.

Editor: Instituto Valenciano de Investigaciones Económicas, S.A.

Primera Edición Noviembre 2002

Depósito Legal: V-4553-2002

IVIE working papers offer in advance the results of economic research under way in order to encourage a discussion process before sending them to scientific journals for their final publication.

\footnotetext{
* We thank John Duffy, Theo Eicher, Oded Galor, Pete Klenow, Pietro Peretto, B. Ravikumar, and John Williams for their comments and suggestions on an earlier version of this paper.

** C. Papageorgiou: Louisiana State University. F. Pérez-Sebastián: Universidad de Alicante.
} 


\title{
MATCHING UP THE DATA ON EDUCATION WITH ECONOMIC GROWTH MODELS
}

\author{
Chris Papageorgiou and Fidel Pérez-Sebastián
}

\begin{abstract}
A B S T R A C T
The growth literature has not yet established how data on education should be introduced in theories involving human capital. Early work used enrolment rates as a proxy of human capital whereas more recently it has utilized measures of average educational attainment taking advantage of new data sets. This paper examines alternative specifications of human capital that may match up with the existing data on education. First, we present a standard neoclassical two-sector growth model that adopts a human capital specification proposed in recent papers. In this model the fraction of individual's time endowment in school is viewed as an investment rate. We show that the optimally chosen educational attainment predicted by the calibrated model is very high and does not correspond to the data. Next, we consider two extensions of the basic model: (a) allow for different elasticities of substitution between skilled and unskilled labor, (b) introduce work experience. We find that neither of the two extensions are able to generate plausible predictions. Finally, we propose an alternative specification of human capital based on a law of motion of educational attainment that successfully matches up with the data.
\end{abstract}

JEL Classification: O15, O41.

Keywords: Educational attainment, Economic growth. 


\section{Introduction}

Even though human capital has been established as one of the primary engines of economic growth and development, it has not yet been established how data on educational attainment should be introduced in growth models. ${ }^{1}$ In this paper we ask the question: In the context of our theories of economic growth, what is an appropriate specification of human capital to which a measure of workers' average years of schooling successfully corresponds? Our primary goal is to search for specifications that, within a simple calibrated growth model, can successfully produce educational attainment levels comparable to those observed in the data.

We start by incorporating the human capital specification suggested by Bils and Klenow (1996) and Jones (1997, 2001), among others, in a very basic neoclassical two-sector growth model. In order to reconcile agents' finite schooling levels with the infinite horizon model, these papers propose interpreting average years of schooling as the fraction of an individual's time endowment allocated to accumulating skill; that is, they interpret average years of schooling as an investment rate. ${ }^{2}$ By using the proposed interpretation of educational attainment this problem is potentially resolved. In addition, this interpretation is shown to be particularly useful in empirical tests of the relationship between income growth and human capital (see Jones (1996)).

Next, we calibrate the model at steady state and compare its predictions to the data. The main finding is that the calibrated model implies an optimally chosen educational attainment level that has a lower bound of more than 30 years, whereas the data support much smaller levels (i.e. 8-14 years). We interpret this finding as suggesting that the human capital technology used in the basic model is too simple.

We then extend the basic specification in two different directions. First, following Mulligan and Sala-i-Martin (2000) and Temple (2001), we allow for different elasticities of substitution between skilled and unskilled labor hoping that assigning appropriate elasticities would produce a specification that works. Our calibration exercise, however, shows that educational attainment levels remain very high regardless of the degree of substitutability between raw and skilled labor. Second, we embed a version of Bils and Klenow (2000) (BK thereafter) human capital specification that includes work experience in the two-sector infinite horizon growth model, and study its equilibrium predictions. ${ }^{3}$ We find that the later extension cannot generate plausible predictions for the average educational attainment, either.

Finally, we present a simple growth model that employs an alternative specification of human

\footnotetext{
${ }^{1}$ It is widely accepted that combining educational attainment data (i.e., Barro and Lee (1993, 2000)) with labor income data obtains a reliable approximation of human capital across countries. Educational attainment data captures formal education whereas labor income data is meant to capture the remaining components of human capital such as informal education (i.e., on-the-job training and work experience, see Stokey (1988)) and health (see Schultz (1989)), for which data are either unavailable or unreliable. In a recent contribution, Mulligan and Sala-i-Martin (2000 p. 216) indicate that employing only labor income data to construct human capital stocks is rather problematic, and that the use of educational attainment data is essential.

${ }^{2}$ More precisely, these papers attempt to take issue with the following potential shortcoming inherent in the infinite horizon neoclassical growth model: when individuals face an infinite horizon they invest in education every period making educational attainment grow with the economy, which is counter-factual.

${ }^{3}$ In an important contribution, BK specify a human capital production function that is based on the "MacroMincer" wage equation, inspired by the labor economics literature, and empirically tested by Heckman and Klenow (1997) and Temple (2001). BK present a finite-lived-agent model of schooling and economic growth that is capable of producing levels of educational attainment that comply with the data. Unlike BK and consistent with the neoclassical framework, the models considered in our paper fall under the infinite-horizon class.
} 
capital. The proposed specification does not include additional variables such as work experience. Instead, it provides a map between schooling investment and human capital accumulation through a law of motion of educational attainment. A calibration exercise reveals that the model is successful in predicting educational attainment levels consistent with those observed in the data.

The rest of the paper is organized as follows. Section 2 investigates the steady-steady properties of a basic infinite horizon two-sector growth model following the specification used in recent papers. Section 3 incorporates a version of BK's human capital specification in our basic model, and investigates its steady-state educational attainment predictions. Section 4 proposes an alternative specification of human capital that features a law of motion of educational attainment. Section 5 concludes.

\section{The Basic Model}

Interpreting an individual's time endowment in school as an investment rate seems, at first pass, to be appealing and worthy of further investigation. As such, the aim of this section is to investigate the implications of a standard two-sector growth model, using the human capital specification suggested in Jones $(1997,2001)$. Even though attention is focused on the neoclassical growth model, it is shown that the results extend to the richer in structure R\&D-based models (see footnote 8).

\subsection{Economic environment}

The economy contains households and firms. Each household consists of identical infinitely-lived agents who are endowed with one unit of time and are involved in two types of activities: consumption goods production, and human capital investment. Labor and technology grow exogenously at rates $n$ and $g_{A}$, respectively. Given neoclassical assumptions, the decentralized and centralized problems obtain same equilibrium outcomes. For ease of exposition we focus on the central planner's problem.

The model economy is characterized by the following two equations. First, the aggregate production function

$$
Y(t)=K(t)^{1-\alpha}\left[A(t) H_{Y}(t)\right]^{\alpha}, \quad 0<\alpha<1 ;
$$

where $Y(t)$ is output at period $t ; K$ is the stock of physical capital; $A$ is the exogenously growing labor-augmenting technology; $H_{Y}$ is skilled-labor input allocated in final output production; and $(1-\alpha)$ is the share of capital stock.

Second, the skilled-labor equation that determines the way by which skill is formed and embodied into labor

$$
H_{Y}(t)=e^{f\left(l_{h}(t)\right)}\left(1-l_{h}(t)\right) L(t) ;
$$

where $l_{h}$ is the fraction of each agent's time endowment allocated to education; and $L$ is labor size. Our choice of skilled-labor technology follows the Mincerian interpretation of human capital. ${ }^{4}$ The

\footnotetext{
${ }^{4}$ The Mincerian interpretation of human capital is originated by Bils and Klenow $(1996,2000)$ and is based on what Heckman and Klenow (1997) call the "Macro-Mincer" wage equation:

$$
\log W_{i t}^{g}=\beta_{0}+\beta_{1} S_{i t}+v_{i t}
$$

where $W_{i t}^{g}$ is the geometric mean wage for country $i$ at time $t ; S$ is mean years of education; and $v$ is a random error. This interpretation has been adopted by many recent papers including Jones $(1997,2001)$ and Hall and Jones
} 
function $f\left(l_{h}(t)\right)$ simply states that productivity from education depents on time in schooling.

Consistent with our analysis, we show later on that by reinterpreting $l_{h}$ as the fraction of an agents' "productive life" spent in school, it becomes a positive function of the average educational attainment level $S$, i.e. $l_{h}=g(S) .{ }^{5}$ Let $\beta$ denote the return to schooling estimated in a Mincerian wage regression: an additional year of schooling raises a worker' efficiency by $\beta \times 100$ percent. It is then easy to show that the Mincerian coefficient is ${ }^{6}$

$$
\beta=f^{\prime}\left(l_{h}\right) g^{\prime}(S)
$$

\subsection{Social planner's problem}

Let lower case letters indicate variables normalized by the size of labor. Also, let $c$ denote per capita consumption. A central planner would choose the sequence $\left\{k(t), c(t), l_{h}(t)\right\}_{t=0}^{\infty}$ to maximize the lifetime utility of the representative consumer subject to the feasibility constraints of the economy. The problem is stated as follows:

$$
\max _{\left\{k, c, l_{h}\right\}} \int_{0}^{\infty} e^{-\rho t} \frac{c(t)^{1-\theta}-1}{1-\theta} d t, 0<\rho<1, \theta>0
$$

subject to,

$$
\begin{gathered}
y=k^{1-\alpha}\left[A e^{f\left(l_{h}\right)}\left(1-l_{h}\right)\right]^{\alpha} \\
\dot{k}=y-c-(n+\delta) k \\
\dot{L}=n L \\
\dot{A}=A g_{A} \\
L_{0}, K_{0}, A_{0} \text { given; }
\end{gathered}
$$

where, $\rho$ is the discount factor; $\theta$ is the inverse of the intertemporal elasticity of substitution; $\delta$ is the depreciation rate of capital; $n$ and $g_{A}$ are the exogenously growing rates of labor and technogy, respectively; and $L_{0}, K_{0}, A_{0}$ are the initial levels of labor, physical capital and technology, respectively. Equation (6) is the standard law of motion of the stock of per capita physical capital, as well as a feasibility constraint.

The first order conditions (FOCs) for the interior solution obtain the optimal share of time allocated to education as

$$
\begin{aligned}
l_{h}^{*} & =1-\frac{1}{f^{\prime}\left(l_{h}^{*}\right)}, \text { if } f^{\prime}\left(l_{h}^{*}\right)>1 \\
& =0, \text { otherwise; }
\end{aligned}
$$

\footnotetext{
(1999), just to name a few. Empirical investigation of the effects of human capital on economic growth based on the "Macro-Mincer" earnings equation is carried out by Krueger and Lindahl (1999) and Temple (2001).

${ }^{5}$ Hereafter, we assume that educational attainment takes the form of formal schooling.

${ }^{6}$ The term $e^{f\left(l_{h}(t)\right)}$ of equation (2) now takes the form $e^{f(g(S))}$, where $S$ is educational attainment as measured by average years of education. The Mincerian coefficient $\beta$ is the first derivative of $f(g(S))$ with respect to $S$, hence $\beta=f^{\prime}(g(S)) g^{\prime}(S)=f^{\prime}\left(l_{h}\right) g^{\prime}(S)$.
} 
where $\left({ }^{*}\right)$ denotes steady-state values. ${ }^{7}$ Equation (9) states that at the margin, the cost of investing one more unit of labor in education must equal its benefit, which is the increase in effective labor from additional schooling in the output sector. ${ }^{8}$ The above equation implies that human capital investment may not occur if the returns to schooling are not sufficiently large. ${ }^{9}$

\subsection{Calibrating the basic model at steady state}

One way to evaluate a model is to formally calibrate its parameters and compare its predictions to the data, as suggested by Klenow and Rodríguez-Clare (1997). When we introduce a human capital technology in a growth model, we aim to pin down the human capital measure that corresponds to the data. Accordingly, we examine our basic model's steady-state predictions regarding the schooling variable, $l_{h}^{*}$.

To start with, we need to establish a range of steady-state educational attainment values that is consistent with evidence. Barro and Lee (2000), in an updated version of their 1993 paper, present data on average educational attainment for 142 countries. They report that in year 2000, average educational attainment of the eighteen richest countries ranged from 7.2 years (Italy) to 12.1 years (U.S.). In an earlier study, Psacharopoulos (1994) reported a maximum value of average educational attainment equal to 13.6 for the U.S. Given this evidence, we suggest that a reasonable steady-state educational attainment value may be between 8 and 14 years. ${ }^{10}$

Next, following Jones (2001), we impose the following explicit function that maps the population's average years of schooling $S$ into the investment variable $l_{h}$ :

$$
l_{h}=\frac{S}{N}
$$

where $N$ is the number of years of "productive life" of an individual. ${ }^{11}$ The relationship between $l_{h}$ and $S$ given by equation (10) is certainly true at steady state. Notice that the optimal schooling

\footnotetext{
${ }^{7}$ As will be shown later on, the assumption $f^{\prime}\left(l_{h}^{*}\right)>1$ is supported by the data. In particular, it is shown that $f^{\prime}\left(l_{h}^{*}\right)$ is equal to the return to education $\beta$, multiplied by the "productive life" of an individual $N$. Given that the lower bound on $\beta$ in the empirical literature is 0.05 , the condition $f^{\prime}\left(l_{h}^{*}\right)>1$ obtains if $N>20$. This is certainly very plausible (in our calibration exercises we use $N=54$ ).

${ }^{8}$ As mentioned at the beginning of this section, our results hold for the R\&D-based model as well. More specifically, in a richer model with monopolistic competition and an R\&D sector, we follow Perez-Sebastian (2000) and specify a law of motion for technology, $\dot{A}=\mu A^{\phi}\left(e^{f\left(l_{h}\right)} l_{A} L\right)^{\lambda}\left(\frac{A^{w}}{A}\right)^{\psi}$, where $H_{A}=e^{f\left(l_{h}\right)} l_{A} L$ is the skilled-labor input employed in R\&D; $A^{w}$ is the stock of existing technology in the world that grows at an exogenous rate $g_{A^{w}} ; \mu$ is a parameter that determines the rate by which a new variety arrives; $\phi$ is a positive externality due to the stock of existing technology; $\lambda$ is a negative externality due to duplication of effort; and $\psi$ is a technology gap parameter. In this extended model our equation (2) becomes $H_{J}(t)=e^{f\left(l_{h}(t)\right)} l_{J}(t) L(t)$, where $l_{J}$ is the fraction of the agent's time endowment allocated to productive activity $J(\forall J=Y, A)$. Solving the optimal problem obtains $g_{A}^{*}=\frac{\lambda n}{1-\phi}$ as in Jones (1995). Along the balanced-growth path, the amount of time allocated to schooling and R\&D is $l_{h}^{*}=1-\frac{1}{f^{\prime}\left(l_{h}^{*}\right)}$ and $l_{A}^{*}=\frac{1-l_{h}^{*}}{\frac{1}{\lambda g_{A}^{*}}\left[r^{*}-n-(\phi-\psi) g_{A}^{*}\right]+1}$ respectively, where $r$ is the return to physical capital. The R\&D-based model's predictions about educational attainment are the same as those of the two-sector neoclassical growth model.

${ }^{9}$ To save space, we hereafter omit the corner solution in the expressions determining the optimal share of labor in schooling.

${ }^{10}$ Since the early 1950s, average educational attainment has been increasing in all industrial countries. For example, Barro and Lee (2000) report that in the U.S. average educational attainment in 1960 was 8.5 years, increasing to 11.9 in 1980, and reaching 12.1 years in 2000. Even though we assume 14 years as a sensible upper bound of educational attainment, higher values that are economically feasible do not change our results qualitatively.

${ }^{11}$ Even though in our model agents are infinitely lived, $N$ is introduced for the purpose of calibrating the model
} 
decision given by equation (9) is now a function of the Mincerian returns to education, as equations (3) and (10) imply that $f^{\prime}\left(l_{h}^{*}\right)=\beta N$.

Finally, in order to examine whether the model's predictions for $l_{h}$ and $S$ comply with the data, we need to choose values for $\beta$ and $N$. Regarding $\beta$, we run a sensitivity analysis employing BK's estimates of Mincerian returns to education: $\beta=\{0.05,0.099,0.15\} .{ }^{12}$ We choose the average "productive life" of individuals to be 54 years (i.e. $N=54$ ). This value is obtained from subtracting 6 years (our assumed pre-schooling period) from 60 years (our assumed retirement age). ${ }^{13}$

Table 1: Predictions of the Basic Model

\begin{tabular}{|lccc|}
\hline \multicolumn{1}{|c}{$\boldsymbol{\beta}$} & $\mathbf{N}$ & $\mathbf{l}^{*}{ }_{\mathbf{h}}$ & $\mathbf{S}^{*}$ \\
\hline \hline 0.05 & 54 & 0.63 & 34.0 \\
0.099 & 54 & 0.81 & 43.9 \\
0.15 & 54 & 0.88 & 47.3 \\
\hline
\end{tabular}

Substituting our chosen values for $\beta$ and $N$ into equation (9), we obtain the predictions presented in Table 1. For $\beta=0.05$, the basic model predicts that average years of education $S^{*}=34.0$. For $\beta=0.099,0.15$, the average years of education $S^{*}$ reaches 43.9 and 47.3 years, respectively. The predicted values of schooling are obviously too high and are far away from our acceptable range of $8-14$ years. This finding suggests that the skilled-labor specification of the basic model is too simple and not consistent with evidence.

\subsection{Substitutability between skilled and unskilled labor}

In this section, we extend the production technology given by equation (1) by relaxing the assumption that raw and skilled labor are perfect substitutes. We then calibrate the model and once again ask whether such a specification is successful in predicting educational attainment consistent with the data. In particular, we examine a nested Constant Elasticity of Substitution (CES) aggregate output specification as follows: ${ }^{14}$

$$
Y=K^{1-\alpha}\left\{A\left[z L_{u}^{v}+(1-z)\left[e^{f\left(l_{h}\right)}\left(1-l_{h}\right) L_{s}\right]^{v}\right]\right\}^{\alpha / v},-\infty<v \leq 1
$$

where $z$ is what Arrow et al. (1961) refer to as the distribution parameter; $L_{u}$ is the number of unskilled workers who allocate zero time in schooling; $L_{s}$ is the number of skilled workers, who allocate a fraction of their time, $l_{h}$, to schooling; and $\sigma=\frac{1}{1-v}$ is the elasticity of substitution between skilled and unskilled labor.

and assigning values to $f^{\prime}\left(l_{h}^{*}\right)$. Furthermore, notice that equation (10) is the consequence of interpreting average years of schooling as the fraction of an individual's time endowment allocated to accumulating skill.

${ }^{12} \mathrm{BK}$ 's estimates of the average returns to schooling fall into the $5 \%-15 \%$ range, with a mean value of $9.9 \%$. BK's estimates are consistent with those in Psacharopoulos (1994).

${ }^{13}$ Our calculation of $N$ is consistent with that of BK who assume $N=54.5$.

${ }^{14}$ Temple (2001) has empirically tested an aggregate production specification similar in spirit to our specification (11). 
In the production function given by equation (11), skilled and unskilled workers are combined into an aggregate by a CES specification. The resulting labor aggregate is then combined with the stock of physical capital by a Cobb-Douglas technology. Dividing both sides of equation (11) by the total number of workers, $L=L_{u}+L_{s}$, and denoting $\frac{L_{u}}{L}=l$ gives

$$
y=k^{1-\alpha}\left\{A\left[z l^{v}+(1-z)\left[e^{f\left(l_{h}\right)}\left(1-l_{h}\right)(1-l)\right]^{v}\right]\right\}^{\alpha / v} .
$$

The social planner's problem can now be stated as

$$
\max _{\left\{k, c, l_{h}, l\right\}} \int_{0}^{\infty} e^{-\rho t} \frac{c(t)^{1-\theta}-1}{1-\theta} d t
$$

subject to,

$$
\begin{gathered}
y=k^{1-\alpha}\left\{A\left[z l^{v}+(1-z)\left[e^{f\left(l_{h}\right)}\left(1-l_{h}\right)(1-l)\right]^{v}\right]\right\}^{\alpha / v} \\
\dot{k}=y-c-(n+\delta) k \\
\dot{L}=n L \\
\dot{A}=A g_{A} \\
L_{0}, K_{0}, A_{0} \text { given. }
\end{gathered}
$$

At steady state, the FOCs for the interior solution imply the following optimal allocation

$$
l_{h}^{*}=1-\frac{1}{f^{\prime}\left(l_{h}^{*}\right)}
$$

and

$$
l^{*}=\frac{1}{1+\left(\frac{z}{1-z}\right)^{\frac{1}{v-1}}\left[e^{f\left(l_{h}^{*}\right)}\left(1-l_{h}^{*}\right)\right]^{\frac{v}{1-v}} .}
$$

Notice that equation (13) is identical to equation (9). This is easy to see by comparing production functions (12) and (5). Let $x$ be the marginal cost of investing in education. In both cases, the marginal benefit from schooling equals $x * f^{\prime}\left(l_{h}\right)\left(1-l_{h}\right)$. That is, cost and benefit change proportionally when we introduce unskilled labor. Hence, the optimal value of $l_{h}$ does not vary.

It is important to notice that $l_{h}^{*}$ now reflects schooling time of skilled workers. Even when we assume that a skilled worker has completed college education and possesses 16 years of schooling, the model predicts values that remain implausibly high.

In addition to the aggregate specification of equation (11), we have also experimented with the specification proposed by Stokey (1996). Stokey's aggregate production technology is consistent with the capital-skill complementarity hypothesis advanced by Griliches (1969) and supported by many researchers (see Hamermesh (1993) p. 113 and more recently Krusell et al. (2000)). Our aggregate specification now takes the form

$$
Y=A\left[z K^{v}+(1-z) L_{u}^{v}\right]^{\alpha / v}\left[e^{f\left(l_{h}\right)}\left(1-l_{h}\right) L_{s}+\xi L_{u}\right]^{1-\alpha} ;
$$

where $z$ is the distribution parameter; and $\xi$ is the relative efficiency of unskilled labor in supplying mental effort. In the above production function, capital and unskilled workers are combined into an 
aggregate by a CES specification. The resulting aggregate measure is then combined with skilled labor and a using a Cobb-Douglas technology. The capital-skill complementarity would hold in this case if the elasticity of substitution between capital and unskilled workers is greater than unity, $\sigma_{K, L_{u}}=\frac{1}{1-v}>1$ or $0<v \leq 1$. Solving the optimization problem delivers the same optimal share of schooling as before, i.e. $l_{h}^{*}=1-\frac{1}{f^{\prime}\left(l_{h}^{*}\right)}$, suggesting that this alternative specification may not be appropriate either.

We conclude that relaxing the assumption that unskilled and skilled labor are perfect substitutes does not improve the results of the basic model.

\section{The Schooling-Experience Model}

Following BK, this section considers a broader concept of human capital by incorporating work experience in the basic model of section $2 .{ }^{15}$ Hereafter, we call this modified model as the "schoolingexperience model."

Equation (2) is now replaced by the following specification:

$$
H_{Y}(t)=e^{f\left(l_{h}(t)\right)+\varepsilon\left(1-l_{h}(t)\right)}\left(1-l_{h}(t)\right) L(t) ;
$$

where $\varepsilon\left(1-l_{h}(t)\right)$ is an implicit function for work experience at period $t$.

\subsection{Social planner's problem}

The planner's problem is stated as

$$
\max _{k, c, l_{h}, l} \int_{0}^{\infty} e^{-\rho t} \frac{c(t)^{1-\theta}-1}{1-\theta} d t
$$

subject to,

$$
\begin{gathered}
y=k^{1-\alpha}\left[A e^{f\left(l_{h}\right)+\varepsilon\left(1-l_{h}\right)}\left(1-l_{h}\right)\right]^{\alpha} \\
\dot{k}=y-c-(n+\delta) k \\
\dot{L}=n L \\
\dot{A}=A g_{A} \\
L_{0}, K_{0}, A_{0} \text { given. }
\end{gathered}
$$

The FOCs for the interior solution obtain the optimal share of average time endowment in education as

$$
l_{h}^{*}=1-\frac{1}{f^{\prime}\left(l_{h}^{*}\right)-\varepsilon^{\prime}\left(1-l_{h}^{*}\right)} .
$$

Notice that $l_{h}^{*}$ is now different from that in the basic model given in equation (9) - there is an additional term, $\varepsilon^{\prime}\left(1-l_{h}^{*}\right)$, appearing in the denominator. Equation (17) implies that in the

\footnotetext{
${ }^{15}$ In addition to work experience, BK allow schooling time to enter in agent's utility function. This assumption is supported by Schultz (1963) who argues that an individual is happier going to school than working. They also correct for quality of education by including teacher human capital in the human capital specification. Both terms raise the marginal benefit from education, and their introduction into our specification would generate larger values of $S^{*}$. This is indeed the opposite effect of what our model needs to generate sensible results.
} 
experience-schooling model, time in formal schooling is reduced because work experience presents an alternative engine of skill formation. Put differently, agents who are now able to enhace their skill level from schooling as well as working, choose an optimal time allocation to formal education that is lower than the one in the basic model.

Table 2: Predictions of the Schooling-Experience Model

\begin{tabular}{|cccc|cccc|}
\hline \multicolumn{3}{|c|}{$\boldsymbol{\gamma}_{1}=0.0512, \boldsymbol{\gamma}_{2}=-0.00071$} \\
$\boldsymbol{\beta}$ & $\mathbf{N}$ & $\mathbf{l}_{\mathbf{h}}^{*}$ & $\mathbf{S}^{*}$ & \multicolumn{4}{|c|}{$\boldsymbol{\gamma}_{1}=0.0846, \boldsymbol{\gamma}_{2}=-0.00108$} \\
$\boldsymbol{\beta}$ & $\mathbf{N}$ & $\mathbf{l}_{\mathbf{h}}^{*}$ & $\mathbf{S}^{*}$ \\
\hline \hline 0.05 & 54 & 0.50 & 27.0 \\
0.099 & 54 & 0.73 & 39.4 \\
0.15 & 54 & 0.83 & 45.0 & 0.05 & 54 & 0.42 & 22.9 \\
0.099 & 54 & 0.66 & 35.5 \\
0.15 & 54 & 0.79 & 42.8 \\
\hline
\end{tabular}

\begin{tabular}{|cccc|}
\hline \multicolumn{4}{|c|}{$\boldsymbol{\gamma}_{1}=0.0934, \boldsymbol{\gamma}_{2}=-0.00110$} \\
$\boldsymbol{\beta}$ & $\mathbf{N}$ & $\mathbf{l}_{\mathbf{h}}^{*}$ & $\mathbf{S}^{*}$ \\
\hline \hline 0.05 & 54 & 0.38 & 20.6 \\
0.099 & 54 & 0.63 & 33.9 \\
0.15 & 54 & 0.78 & 42.0 \\
\hline
\end{tabular}

\subsection{Calibrating the schooling-experience model at steady state}

For the calibration exercise, we need to assign values to $\varepsilon^{\prime}\left(1-l_{h}\right)$. To do this, we employ estimates of Mincerian returns on experience, which are in general based on the following quadratic equation:

$$
\varepsilon(p(E))=\gamma_{1} E+\gamma_{2} E^{2}
$$

where $E$ is the worker's years of experience; and $p$ is an explicit function that maps $E$ into the investment variable $\left(1-l_{h}\right)$. This quadratic form implies a Mincerian return on experience equal to $\varepsilon^{\prime}(p(E))=\varepsilon^{\prime}\left(1-l_{h}\right) p^{\prime}(E)=\gamma_{1}+2 \gamma_{2} E$. Hence,

$$
\varepsilon^{\prime}\left(1-l_{h}\right)=\frac{\gamma_{1}+2 \gamma_{2} E}{p^{\prime}(E)} .
$$

Consistent with equation (10), and for the purpose of this calibration exercise, we assume that

$$
\left(1-l_{h}\right)=p(E)=\frac{E}{N} .
$$

In equation $(20)$, the term $\left(1-l_{h}\right)$ is interpreted as the fraction of the individuals' productive life in the work-place accumulating experience. Finally, expressions (19) and (20) deliver

$$
\varepsilon^{\prime}\left(1-l_{h}^{*}\right)=N\left[\gamma_{1}+2 \gamma_{2}\left(1-l_{h}^{*}\right) N\right] .
$$

Values for $\gamma_{1}=0.0512$ and $\gamma_{2}=-0.00071$ are obtained from BK, and they reflect the average estimates of the Mincerian returns to experience across 52 countries. ${ }^{16}$ Recalling that $f^{\prime}\left(l_{h}^{*}\right)=\beta N$,

\footnotetext{
${ }^{16}$ For more discussion on these estimates see BK (p.1167 and appendix B).
} 
we can now recover $l_{h}^{*}$ using equations (17) and (21). ${ }^{17}$ The predicted values of average years in schooling are given in Table 2. For $\beta=0.05$ the value of $S^{*}$ is 27.0. As expected this value is lower than that in the basic model (see Table 1), but still much higher than our acceptable range of $8-14$ years. For $\beta$ equal to 0.099 and 0.15 , the implied values of $S^{*}$ are implaussible.

The above numbers are certainly sensitive to the choice of $\gamma_{1}$ and $\gamma_{2}$. Recall from equation (17) that the optimal value of $l_{h}^{*}$ and therefore $S^{*}$ decrease with the return to experience. As a robustness check of our results, we take the average values for the 10 countries in the BK sample with largest $\gamma_{1}$; this obtains $\gamma_{1}=0.0846$ and $\gamma_{2}=-0.00108$. As we see in Table 2 , the minimum educational attainment is still large, 22.9 years. If we go even further and calculate the average for the 5 countries with the largest $\gamma_{1}$, we get $\gamma_{1}=0.0934$ and $\gamma_{2}=-0.00110$. Table 2 reveals that the optimal number of years of education in this case is 20.6 , again implausibly high. ${ }^{18}$

A parameter to which the predictions of both the basic and schooling-experience models are sensitive is the individual's productive life, $N$. It is easy to show that in both models, average years of schooling $S^{*}$ declines with $N$. In the basic model, $S^{*}=14$ (our upper bound) only when $N=34$, whereas in the most favorable case of the schooling-experience model, $S^{*}=14$ when $N=47$. Both values of $N$ are lower than our assumed parameter $N=54 .^{19}$

Unlike the basic model, the schooling-experience model can raise the marginal cost of education investment through the experience parameter. This reduces the optimal amount of schooling time and consequently the steady-state level of educational attainment. The predicted values, however, remain implausibly high. We conclude that even though the introduction of a working-experience term in the human capital specification improves the educational attainment predictions of the model, it is not sufficient to make these predictions plausible.

\section{An Alternative Specification of Skilled-Labor}

In this section, we offer an alternative skilled-labor specification that delivers educational attainment levels that are consistent with those in the data. An attractive feature of the proposed specification is that it does not include additional variables such as work experience, which makes it easy to incorporate into existing growth models.

Final output production is once again given by equation (1). Human capital per capita is now expressed as

$$
h(t)=e^{f(S(t))} .
$$

The derivative $f^{\prime}(S(t))$ represents the returns to schooling estimated in a Mincerian wage regression. As in the basic model, we assume that at period $t$ agent $i$ invests a fraction, $l_{h}(t, i)$, of his time in education and that population grows at rate $n$. Years of schooling accumulate through educational

\footnotetext{
${ }^{17}$ Combining equations (17) and (21) results in a quadratic equation. It turns out that for each of three quadratic equations associated with the values of $\beta$, one of two real roots is economically infeasible (greater than unity). We report the feasible values of $l_{h}^{*}$, and the corresponding values of $S^{*}$. Once again, $S^{*}$ is recovered using equation (10).

${ }^{18} \mathrm{~A}$ value of $\gamma_{1}$ equal to 0.0934 represents the average in the BK sample plus 1.96 standard deviations. It is also important to notice that, in the BK sample, larger values of $\gamma_{1}$ are generally associated with lower values of $\gamma_{2}$, with a correlation coefficient between the two parameters of -0.61 .

${ }^{19}$ As mentioned previously, BK use $N=54.5$ which is very close to our chosen parameter. They calculate $N$ by taking the average life expectancy 60.5 (see Barro and Lee (1993)) minus 6 years, the typical pre-schooling period.
} 
investment. Average educational attainment equals

$$
S(t)=\frac{1}{L(t)} \int_{0}^{t}\left(\int_{0}^{L(j)} l_{h}(j, i) d i\right) d j .
$$

Differentiating expression (23) with respect to $t$ delivers the following law of motion of the average educational attainment, $S$ :

$$
\dot{S}(t)=l_{h}^{e}(t)-n S(t)
$$

where $l_{h}^{e}(t)=[1 / L(t)]\left[\int_{0}^{L(t)} l_{h}(t, i) d i\right]$ is the economy-wide fraction of time allocated to acquiring skills. This law of motion is equivalent to the standard motion of physical capital. Equation (24) says that, at the aggregate, workers' average educational attainment increases with the fraction of time that agents invest in schooling, but (exogenously) declines with the increase of population.

The new human capital formulation introduces an externality. Equations (1), (22) and (24) imply that labor productivity depends on the average educational attainment in the economy. A worker's investment in education, therefore, has positive external effects on other workers productivity. For simplicity, we keep focusing on the centralized solution.

\subsection{Social planner's problem}

The social planner's problem is the following:

$$
\max _{\left\{k, c, l_{h}, S\right\}} \int_{0}^{\infty} e^{-\rho t} \frac{c(t)^{1-\theta}-1}{1-\theta} d t
$$

subject to,

$$
\begin{gathered}
y=k^{1-\alpha}\left[A e^{f(S)}\left(1-l_{h}^{e}\right)\right]^{\alpha} \\
\dot{k}=y-c-(n+\delta) k \\
\dot{S}=l_{h}^{e}-n S \\
\dot{L}=n L \\
\dot{A}=A g_{A} \\
L_{0}, K_{0}, A_{0}, S_{0} \text { given. }
\end{gathered}
$$

We construct the Hamiltonian, and get the FOCs for the interior solution. After some algebra we show that the Euler equation that characterizes the optimal allocation of labor to human capital investment is

$$
f^{\prime}(S)\left(1-l_{h}^{e}\right)+\left[\frac{\dot{y}}{y}+\frac{i_{h}^{e}}{1-l_{h}^{e}}\right]=r ;
$$

where $r$ is the interest rate that is given by

$$
r=(1-\alpha) \frac{y}{k}-\delta=\rho+\theta \frac{\dot{c}}{c}+n .
$$

Equation (26) is the standard Euler condition for consumption. Expression (25) can be interpreted as an arbitrage condition. The LHS of equation (25) is the returns to sacrificing one unit of output 
for acquiring schooling. The first term represents the dividend from the increase in effective labor. The term in brackets represents the capital gain/loss, which is equal to the percentage change in the price of education - notice that the shadow price of having additional units of education equals the marginal productivity of labor in output production, $\frac{\alpha y}{1-l_{h}}$. The RHS of equation (25) captures the opportunity cost of schooling investment, given by the interest rate. In equilibrium, both sides must be equalized.

Let $g_{j}$ be the steady-state growth rate of variable $j$. Along the balanced growth path $g_{y}=g_{c}$, and $i_{h}^{e}=0$. Euler equations (25) and (26) then imply that the optimal share of labor in schooling is

$$
l_{h}^{e *}=1-\left[\frac{n+\rho+(\theta-1) g_{y}}{f^{\prime}\left(S^{*}\right)}\right] .
$$

The optimal education investment depends directly on its current return $f^{\prime}\left(S^{*}\right)$ and the future benefits, which grow with $g_{y}$, of applying the acquired knowledge. As expected, the optimal education investment declines with the preference parameters $\rho$ and $\theta$, and the population growth rate $n$.

\subsection{Calibrating the alternative model at steady state}

We choose the standard values $g_{y}=0.02, \rho=0.04, n=0.016$, and $\theta \in[1,2]$ from the existing literature. ${ }^{20}$ We then use equation (27) to generate values for $l_{h}^{e *}$ and $S^{*}$. Table 3 presents estimates of $l_{h}^{e *}$ and $S^{*}$ for different values of $\theta=\{1,2\}$ and $\beta=\{0.05,0.068,0.099,0.15\}$.

Table 3: Predictions of proposed model without an explicit function for $f^{\prime}(S)$

\begin{tabular}{|cccc|cccc|}
\hline $\boldsymbol{\beta}$ & $\boldsymbol{\theta}$ & $\mathbf{l}_{\mathbf{h}}^{\mathbf{e}}$ & $\mathbf{S}^{*}$ & $\boldsymbol{\beta}$ & $\boldsymbol{\theta}$ & $\mathbf{l}_{\mathbf{h}}^{\mathbf{e} *}$ & $\mathbf{S}^{*}$ \\
\hline \hline 0.05 & 1 & - & - \\
0.068 & 1 & 0.18 & 11.0 \\
0.099 & 1 & 0.43 & 27.1 \\
0.15 & 1 & 0.63 & 39.2
\end{tabular} \begin{tabular}{cccc}
0.05 & 2 & - & - \\
0.068 & 2 & - & - \\
0.099 & 2 & 0.23 & 14.5 \\
0.15 & 2 & 0.49 & 30.0 \\
\hline
\end{tabular}

We find that for $\beta=0.068$ (the OECD average in Psacharopoulos (1994)) and $\theta=1$, the calibrated share of labor in schooling is $l_{h}^{e *}=0.18$, and the resulting mean years of schooling is 11.0. In the case where $\beta=0.097$ and $\theta=2$, the model predicts that $l_{h}^{e *}=0.23$, and $S^{*}=14.5$ which is close to our upper value of 14 years and the value reported by Psacharopoulos (1994) for the U.S. ( $S_{U . S .}^{*}=13.6$ years). These estimates are more consistent with the data.

So far, we have taken $\beta$ as exogenous to generate predictions. But the Mincerian return to schooling is actually a function of $S$. A tougher test of the proposed model is to give an explicit form to $\beta(S)$ and examine whether the predictions still comply with the data. Following BK, we assume that $\beta=\eta \varphi S_{t}^{\varphi-1}$, where $\beta>0$, and $0<\varphi \leq 1$, and consider three pairs for $\eta$ and $\varphi$,

\footnotetext{
${ }^{20}$ We set the per capita output growth rate $g_{y}$ to $2 \%$ which is the approximate post-war per capita output growth rate for the U.S. We also set the growth rate of population $n$ to match the average labor force growth rate in the U.S. during the period 1950-1980. A range of estimates of the inverse of the intertemporal elasticity of substitution $\theta$ are taken from Hall (1988), Attanasio and Weber (1993), and a very valuable recent contribution by Guvenen (2001).
} 
$\{0.76,0.42\},\{0.25,0.72\}$, and $\{0.099,1\} .{ }^{21}$ We then exploit an equilibrium relationship between $l_{h}^{e *}$ and $S^{*}$ obtained by the model. In particular, because at steady state $l_{h}^{e}$ remains constant, the motion equation (24) implies that so does $S^{*}$ - otherwise $g_{S}$ can not be a constant - and therefore

$$
S^{*}=\frac{l_{h}^{e *}}{n} .
$$

Equation (27) becomes

$$
l_{h}^{e *}=1-\left[\frac{n+\rho+(\theta-1) g_{y}}{\eta \varphi\left(\frac{l_{h}^{e *}}{n}\right)^{\varphi-1}}\right] .
$$

It is easy to show that equation (29) has a unique root but does not have an analytic solution when $0<\varphi<1$; we therefore use numerical approximation methods to obtain solutions.

\begin{tabular}{|c|c|c|c|c|c|c|c|c|c|}
\hline$\eta$ & $\varphi$ & $\theta$ & $\mathrm{l}_{\mathrm{h}}^{*}$ & $\mathbf{S}^{*}$ & $\eta$ & $\varphi$ & $\theta$ & $\mathbf{l}_{\mathbf{h}}^{*}$ & $\mathbf{S}^{*}$ \\
\hline 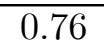 & 0.42 & 1 & 0.21 & $\overline{13.3}$ & 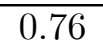 & $\overline{0.42}$ & $\overline{2}$ & 0.15 & $\overline{9.1}$ \\
\hline 0.25 & 0.72 & 1 & 0.30 & 18.5 & 0.25 & 0.72 & 2 & 0.17 & 10.9 \\
\hline 0.099 & 1 & 1 & 0.43 & 27.1 & 0.099 & 1 & 2 & 0.23 & 14.5 \\
\hline
\end{tabular}

Table 4: Predictions of proposed model with $f^{\prime}(S)=\eta \varphi S^{\varphi-1}$

The estimates of this calibration exercise are presented in Table 4. We find that for the value of $\theta=2$ all three pairs of $\{\eta, \varphi\}$ obtain plausible values for $l_{h}^{*}$ and $S^{*}{ }^{22}$ The triplet $\{\eta=0.76, \varphi=$ $0.42, \theta=1\}$ also delivers plausible values. ${ }^{23}$

The main finding here is that our calibrated model is able to deliver levels of educational attainment consistent to those in the data. In other words, for values of $\theta \in[1,2]$ there is a value of $f^{\prime}(S)$ (or a pair of $\eta$ and $\varphi$ ) that provides educational attainment levels that are consistent with those in the data (i.e. $S^{*} \in[8,14]$ ). This is the result of the dynamic structure of the proposed human capital accumulation technology that is able to reduce sufficiently the overall returns to education.

\section{Conclusion}

This paper has searched for specifications of human capital that can match existing data on educational attainment with economic growth models. We have first examined a simple two-sector

\footnotetext{
${ }^{21} \mathrm{BK}$ regress country estimates of Mincerian returns on country schooling levels in Psacharopoulos (1994) 56country sample. They obtain the estimate $1-\varphi=0.58$ which implies diminishing Mincerian returns to schooling across nations. They also consider two other values; $1-\varphi=0.28$ (their point estimate minus two standard errors) and $1-\varphi=0$ (no diminishing returns). For each value of $\varphi$ they set the value $\eta$ so that the mean of $\beta=\eta \varphi S^{\varphi-1}$ equals the mean Mincerian return across Psacharopoulos' sample of 56 countries, which is 0.099.

${ }^{22}$ Notice that the last row of table 4 is identical to the next to last row of table 3 . This is because when $\{\eta, \phi\}=$ $\{0.099,1\}$ the two specifications are identical.

${ }^{23} \mathrm{~A}$ sensitivity analysis shows that our results are robust to changes in the parameters $g_{y}, \rho$ and $n$.
} 
growth model with a human capital specification found in recent papers. Calibrating the basic model reveals several caveats associated with this specification, and casts doubts in its use in theoretical and empirical work. In particular, the model predicts that the optimally chosen educational attainment is between 34 and 47 years, whereas the actual levels observed in the data are between 8 and 14 years. Two alternative models that employed a CES specification to aggregate skilled and unskilled labor have also been examined without any success.

We have then followed Bils and Klenow (2000) by incorporating work experience in addition to schooling in the basic model. Our main result is that even though incorporating experience in the human capital specification improves the educational attainment predictions of the model, it is not sufficient to make these predictions plausible.

Finally, we have presented an alternative specification of human capital that incorporates an explicit law of motion of the mean years of education. An important feature of the proposed specification is that it does not include additional variables such as work experience, which makes it easy to incorporate into existing theoretical growth models and easy to adopt in growth accounting exercises. The proposed model is a standard infinite-horizon neoclassical growth model that uses parameters found in the literature. Simple calibration exercises of the model at steady state reveal that the proposed specification of human capital is successful in replicating the observed data on educational attainment.

It is obvious that our results are conditional on the parameter values chosen to carry out the calibration exercises. A parameter to which the predictions of the basic and schooling-experience models are especially sensitive, is the individual's "productive life," $N$. Our sensitivity analysis on $N$ reveals an important weakness of the human capital specification employed in recent models. These models take the market return to human capital investment as contemporaneous and immediate, whereas in practice the return to schooling is accrued over an individual's lifetime. This leads to overstating the return to schooling, and predicting too high educational attainment levels. Introducing experience, and decreasing the individual's "productive life" are necessary adjustments to reduce the return to schooling in the basic model.

In contrast, our proposed human capital specification does not require experience, or lower "productive life" to obtain desirable predictions. This is because when human capital accumulates, preference parameters such as $\rho$ and $\theta$ that determine intertemporal decisons, discount the return to schooling sufficiently to deliver sensible values of the average educational attainment. Another attractive feature of our human capital specification is that it may be used for off-steady-state analysis as well. Further work with our proposed specification revealed that outside the balanced growth path, enrollment rates and the average educational attainment are negatively correlated, which is the relationship that dominates the data (see Pritchett (1997) pp. 27-30).

The conclusions of the paper for future research are twofold. First, incorporating the proposed human capital specification into an R\&D-based model and examining the transitional dynamic properties of the model is a promising next step. Second, using the reduced form equation implied by our alternative specification, one can reexamine accounting exercises such as those in Klenow and Rodríguez-Clare (1997a), Hall and Jones (1999) and Temple (2001). 


\section{References}

Arrow, K., Chenery, H., Minhas, B. and Solow, R., "Capital-Labor Substitution and Economic Efficiency," Review of Economics and Statistics, 43:225-250, 1961.

Attanasio, O. and Weber, G., "Consumption, the Interest Rate and Aggregation," Review of Economic Studies, 60:631-649, 1993.

Barro, R. and Lee, J.,"International Comparisons of Educational Attainment," Journal of Monetary Economics, 32:363-394, 1993.

Barro, R. and Lee, J., "International Data on Educational Attainment: Updates and Implications," CID working paper\#42, 2000.

Bils, M. and Klenow, P., "Does Schooling Cause Growth or the Other Way Around?" working paper, University of Rochester, 1996.

Bils, M. and Klenow, P., "Does Schooling Cause Growth?" American Economic Review, 90:1160$1183,2000$.

Griliches, Z, "Capital-Skill Complementarity," Review of Economics and Statistics, 51:465-468, 1969.

Guvenen, M.F., "Mismeasurement of the Elasticity of Intertemporal Substitution: The Role of Limited Stock Market Participation," working paper, Carnegie Mellon University, 2001.

Hall, R., "Intertemporal Substitution in Consumption," Journal of Political Economy, 96:339357,1988

Hall, R. and Jones, C., "Fundamental Determinants of Output Per Worker Across Countries," Quarterly Journal of Economics, 114:83-116, 1999.

Hamermesh, D.S., Labor Demand, 2nd Ed., Princeton: Princeton University Press, 1993.

Heckman, J. and Klenow, P., "Human Capital Policy," working paper, University of Chicago, 1997.

Jones, C.I., "R\&D-Based Models of Economic Growth," Journal of Political Economy, 103:759$784,1995$.

Jones, C.I., "Human Capital, Ideas, and Economic Growth," working paper, Stanford University, 1996.

Jones, C.I., "Convergence Revisited," Journal of Economic Growth, 2:131-153, 1997.

Jones, C.I., "Sources of U.S. Economic Growth in a World of Ideas," American Economic Review, forthcoming, 2001.

Klenow, P. and Rodríguez-Clare, A., "Economic Growth: A Review Essay," Journal of Monetary Economics, 40:597-617, 1997.

Krueger, A.B. and Lindahl, M., "Education for Growth in Sweden and the World," NBER working paper\#7190, 1999.

Krusell, P., L.E. Ohanian, J-V. Ríos-Rull and Violante G.L., "Capital-Skill Complementarity and Inequality: A Macroeconomic Analysis," Econometrica, 68:1029-1053, 2000.

Mulligan C.B., and Sala-i-Martin, X., "Measuring Aggregate Human Capital," Journal of Economic Growth, 5:215-252, 2000.

Perez-Sebastian, F., "Transitional Dynamics in an R\&D-Based Growth Model with Imitation: Comparing its Predictions to the Data," Journal of Monetary Economics, 45:37-61, 2000. 
Pritchett, L., "Where Has All the Education Gone?" World Bank working paper\#1581, 1997.

Psacharopoulos, G., "Returns to Investment in Education: A Global Update," World Development, 22:1325-1343, 1994.

Schultz, T.P., The Economic Value of Education, Columbia University Press, 1963.

Schultz, T.P., "Returns to Women Education," Population, Health, and Nutrition Department, World Bank working Paper\#89/001, 1989.

Stokey, N.L., "Learning by Doing and the Introduction of New Goods," Journal of Political Economy, 96:701-717, 1988.

Stokey, N.L., "Free Trade, Factor Returns, and Factor Accumulation," Journal of Economic Growth, 1:421-447, 1996.

Temple, J.R.W., "Generalizations That Aren't? Evidence on Education and Growth," European Economic Review, 45:905-918, 2001. 